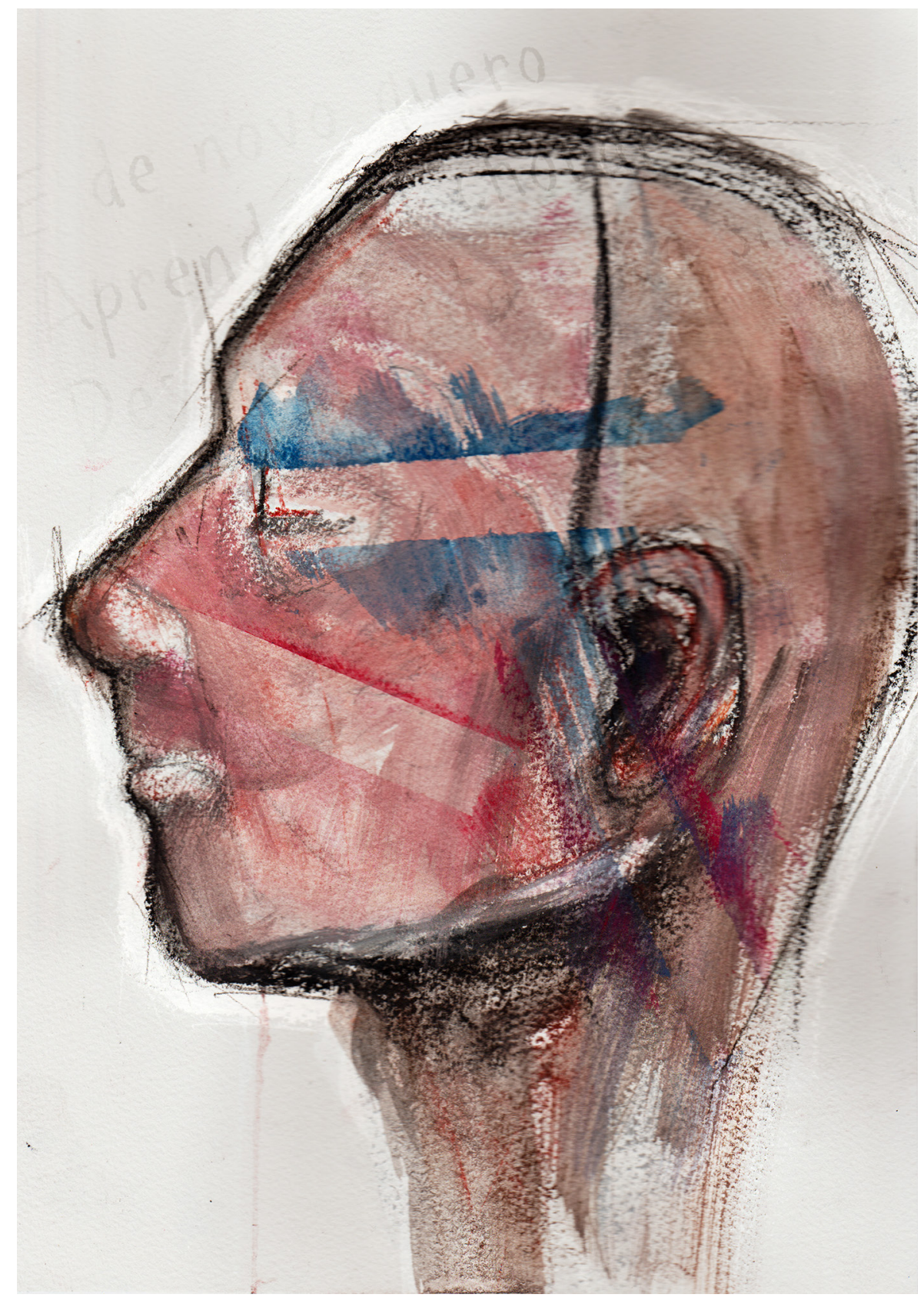


AUToR: Guillermo Calviño 


\title{
Vicente Risco perante a censura franquista: Leria, 0 porco de pé e La puerta de paja
}

\author{
Xosé Manuel Dasilva \\ Universidade de Vigo \\ https://orcid.org/0000-0002-3360-6995
}

[Recibido, 9 decembro 2020; aceptado, 6 maio 2021]

[Dasilva, X.-M. (2021). Vicente Risco perante a censura franquista: Leria, O porco de pé e La puerta de paja. Boletín Galego de Literatura, 58, "Estudos", 5-27] DOl http://dx.doi.org/10.15304/bgl.58.7319

RESUMO A finalidade principal deste estudo consiste en profundar nas diferentes dificultades que encontraron os volumes Leria (1961) e O porco de pé e outras narracións (1972), de Vicente Risco, na tramitación da autorización necesaria ante a censura franquista para a súa publicación. Tamén se abordan algunhas das desventuras do mesmo tipo padecidas pola novela en español La puerta de paja (1953), que se converteu en finalista do reputado Premio Nadal. Neste terceiro caso proponse á vez un criterio apropiado para a restauración da obra, editada ata agora con amputacións ordenadas polo Ministerio de Información y Turismo, por unha parte, ou sen axustarse ao discurso que o autor corroborou, por outra.

PALABRAS CHAVE: Literatura galega; Vicente Risco; censura franquista; Leria; O porco de pé; La puerta de paja.

ABSTRACT The main purpose of this study is to delve into the different difficulties encountered by the volumes Leria (1961) and O porco de pé e outras narracións (1972), by Vicente Risco, in the processing of the necessary authorization before Franco's censorship for their publication. Some of the misadventures of the same kind suffered by the novel in Spanish La puerta de paja (1953), which became a finalist for the renowned Nadal Prize, are also addressed. In this third case, an appropriate criterion is proposed for the restoration of the work, published up to now with amputations ordered by the Ministry of Information and Tourism, on the one hand, or without adjusting to the discourse that the author corroborated, on the other.

KErwORDS: Galician literature; Vicente Risco; Francoist censorship; Leria; O porco de pé; La puerta de paja.

\section{Introdución}

A actuación represiva da censura franquista presenta como trazo esencial o seu despotismo obstinado, máis aínda no que se refire ás literaturas galega, vasca e catalá pola súa situación non hexemónica no escenario estatal. Tal 
circunstancia xa se puña de manifesto visiblemente, con abonda elocuencia, na denuncia contra a persecución da lingua galega que se difundiu na VIII Conferencia Xeral da UNESCO, celebrada entre o 12 de novembro e o 13 de decembro de 1954 en Montevideo, onde estaba previsto que se ratificase a admisión de España como membro de pleno dereito da organización.

Neste documento reivindicativo, resaltábase primeiramente a natureza omnímoda do control que exercía o Estado, de forma que non podía circular, segundo se aducía, "ren, ausolutamente ren" que con antelación non fose "eisaminado e autorizado" (Sen sinatura, 1954, p. 6). En segundo termo, subliñábase a condición totalitaria da censura, posto que nin os autores nin os editores, conforme se alegaba, contaban con "regras ouxetivas a que aterse" (Sen sinatura, 1954, p. 6). A este respecto, lembrábase que o ditame do censor se rexía exclusivamente "pol-o seu avaliamento persoal ou por consiñas internas da censura, ás cales o autor e mais o imprentador son alleos" (Sen sinatura, 1954, p. 6). En terceiro lugar, recriminábase para terminar o carácter "gubernativo e non legal das prohibicións", xa que as máis delas, como se sostiña, non figuraban "en ningunha lei escrita e promulgada" (Sen sinatura, 1954, p. 6).

Certamente, un modelo palpable de todo o exposto foi o que ocorreu coas edicións de Leria e O porco de pé e outras narracións, de Vicente Risco (1961, 1972), promovidas pola editorial Galaxia, no seu percorrido administrativo polo aparato opresivo franquista. Alén da famosa sátira protagonizada por don Celidonio, que vira a luz baixo o selo de Nós había máis de corenta anos (Risco, 1928), cómpre significar que no segundo volume se incluía o conxunto da produción narrativa en galego do autor ourensán, pertencente por completo á fase anterior á Guerra Civil. É dicir, o relato Do caso que lle aconteceu ao Dr. Alveiros (Risco, 1919), a ficción inconclusa Os europeos en Abrantes (Risco, 1927a, 1927b) e as historias breves $O$ lobo da xente e $A$ trabe de ouro e a trabe de alquitrán (Risco, 1925).

Outro expoñente non menos revelador dos comportamentos arbitrarios do lapis vermello detéctase na primeira novela en español de Risco, La puerta de paja (Risco, 1953), que logrou unha aceptable acollida da crítica tras non triunfar no postremo intre nas deliberacións do Premio Nadal, alentado por Ediciones Destino. Brindada aos lectores por Planeta, competidora da anterior, La puerta de paja non se deu salvado integralmente dos estorbos que 
atopou nas dependencias ministeriais. Chegaría ás librerías, xa que logo, con algúns segmentos textuais excluídos, os cales se restableceron posteriormente de acordo cunha fórmula non de todo adecuada.

Nas páxinas sucesivas levarase a cabo o exame pormenorizado dos diversos contratempos que Leria, O porco de pé e outras narracións e La puerta de paja experimentaron no seu paso pola censura, órgano relevante do poder ditatorial, manexando para iso preferentemente materiais de primeira man.

\section{O expediente de censura de Leria}

Nos albores dos anos 60, o feixe de ensaios Leria suxeitouse á vixilancia da censura, aínda que afortunadamente sen incidentes ${ }^{1}$. O autor introducira reformas, con todo, nalgunhas achegas, como "Nós, os inadaptados". Ricardo Carballo Calero (1975, p. 637) reparou nesta sutil operación, mais sen inclinarse por delimitar a causa con pleno convencemento:

Este ensaio fora pubricado denantes na revista Nós (número 115, 1933). Risco di que, ao reproducir o traballo, déixao ir como está (Leria, páx. 44); pero suprime o prólogo, que sustitúi por outro -no que figuran antre aspas unhas liñas do primitivo- e amaina o seu nacionalismo galego -¿por temor á censura oficial? ¿por repudio espontáneo do radicalismo anterior?

Francisco J. Bobillo de la Peña (1980, pp. 58-59) tamén se decataría das diverxencias entre as dúas versións de "Nós, os inadaptados", que cualificaba pola súa parte de tenues, atribuíndoas en idéntica proporción aos móbiles insinuados por Carballo Calero:

Entre ambos se advierten leves modificaciones, realizadas por el propio Risco al preparar la edición Leria, con respecto al texto original. Tales modificaciones producto parcial de la autocensura y también de la propia evolución risquiana, no alteran, sin embargo, la sustancialidad del artículo.

\footnotetext{
A documentación non editada que se cita neste artigo está depositada na Fundación Penzol, na Biblioteca-Arquivo Francisco Fernández del Riego, na Fundación Vicente Risco, na Biblioteca Municipal do Porto e no Archivo General de la Administración. Desexamos testemuñar o noso agradecemento a Teresita Aboal Somoza, da Biblioteca Central da Universidade de Vigo, a Benito Ramírez Abal, da Fundación Penzol, e a Marta Irene de Gonçalves Rua, da Biblioteca Municipal do Porto, pola súa inestimable colaboración.
} 
O certo é que Risco non se cinguira en sentido estrito a retocar tan só este ensaio. De feito, $M^{a}$ Jesús Lorenzo Modia (1994, p. 121) apreciou distintas transmutacións en "Dédalus en Compostela (Pseudoparáfrase)" ao cotexar minuciosamente o texto orixinal. É máis, nunha carta de Ramón Piñeiro a Basilio Losada do 14 de maio de 1963, declarábase que Risco, sen influencia de ninguén, seleccionara os traballos reunidos en Leria, eludindo premeditadamente "os que tiñan un senso máis craro de apostolado galego" (Piñeiro e Losada, 2009, p. 231).

Ben-Cho-Shey, representante habitual de Galaxia na xestión destes trámites, pedía licenza para Leria na Sección de Inspección de Libros o 20 de setembro de 1960. O falanxista Miguel Piernavieja sería o responsable de escudriñar as galeradas, quen se pronunciaba, transcorrido un mes, con estas sintéticas palabras de signo non hostil: "Colección de artículos y ensayos breves: la morriña, el futurismo, romanticismo, cultos, supersticiones, etc., relacionados con la idiosincrasia gallega. Nada fundamental que oponer".

Francisco Fernández del Riego facía saber persoalmente a Risco, en carta do 30 de novembro de 1960, que a edición se tolerara na súa totalidade, sen o máis mínimo atranco:

Xa lle diría o Xocas que a súa Leria veu aprobada pola censura. Estase compoñendo en Pontevedra o texto do libro, e calculamos que no mes de xaneiro haberá exemprares dispostos pra lle remesar.

\section{$O$ expediente de censura d'O porco de pé e outras narracións}

Nunha carta do 7 de novembro de 1972, Fernández del Riego informaba a Piñeiro sobre o remate do proceso de preparación d'O porco de pé e outras narracións: "Xa está composto o libro do Risco. Conviña que me mandases o texto para a solapa". Como acto subseguinte, a solicitude preceptiva de permiso rexistrábase o 21 de novembro da man de Ben-Cho-Shey, de novo en nome de Galaxia, ante o servizo Ordenación Editorial, adscrito á Dirección General de Cultura Popular, do Ministerio de Información y Turismo. Un día despois, resolvíase que as galeradas entregadas se traspasasen ao lector -eufemismo este no canto de censor- $\mathrm{n}^{\circ} 18$, que resultaba chamarse Ángel Aparicio pola sinatura lexible que asoma na documentación. 
O devandito censor emitía o seu informe o 30 de novembro, onde propuña que se permitise $O$ porco de pé e outras narracións sempre que se borrasen algunhas pasaxes especificadas polo miúdo. Velaquí, integramente, o seu parecer:

En El puerco de pie y otras narraciones el autor nos brinda una crítica dura, agraz y despectiva de la sociedad española, encarnada en las sencillas comunidades aldeanas de Galicia, en lo político-social-cultural-económico. Es ingenioso y muestra su seguro conocimiento del estilo narrativo, pero también sabe sembrar aquí y allá su semilla disidente con expresiones en las que manifiesta su procominismo [sic] (págs. 8-33-76-94-206), filomasonería (48), el repugnante espectáculo del aquelarre y sacrílego de la magia negra (66), su tendencia separatista (93-94), su anticlericalismo (196) y finalmente hace un juicio despectivo de la península ibérica como parte de Europa (198). Autorizado con tachaduras.

É obvio que o censor en cuestión, o cal daba mostras de descoñecer a significación de Risco na cultura galega, efectuou unha lectura do volume por enteiro descontextualizada. No que atangue a $O$ porco de pé, non tiña en conta que nacera como visión sarcástica da sociedade no ciclo ditatorial de Primo de Rivera. O propio Risco así llo manifestaba a Carlos de Passos, intelectual portugués con quen mantiña esporadicamente correspondencia, desvelando ademais a influencia de James Joyce no relativo a algúns recursos formais. Nunha carta do 21 de abril de 1935, indicaba con extraordinaria claridade:

Envieille todos aquiles libros dos que tiña eixemprares na miña casa ou nas librerías de Ourense. Percurei $O$ porco de pé, mais eiquí n-Ourense non hai; mandeino pedir a Santiago, e se aínda quedan, enviareille un co maor gusto, somentes pra satisfacer a súa curiosidade. É unha farsada satírica da sociedade galega, moi influída no procedemento literario pol-as cousas de James Joyce. ${ }^{2}$

2 É oportuno consignar que descubrimos e consultamos exhaustivamente a correspondencia de Carlos de Passos con persoeiros galegos na Biblioteca Municipal do Porto, onde se custodia, no mes de novembro de 2017. Aos poucos días, con ocasión do evento Xornada Conmemorativa do 70 Aniversario da Publicación de Cómaros Verdes, en Vilagarcía de Arousa, comentamos tal experiencia, confidencialmente, con Xesús Alonso Montero e Patricia Arias Chachero, amosándolles ademais reproducións fotográficas dese fondo documental. En datas recentes, a mencionada Patricia Arias Chachero (2020) deu a coñecer repentinamente o artigo "O historiador portugués Carlos de Passos e a súa relación cos intelectuais galegos. O epistolario con Vicente Risco (1934-1954)". Polo demais, convén salientar que na Biblioteca Municipal do Porto tamén se conservan cartas de Ramón Otero Pedrayo a Carlos de Passos, facéndose referencia puntual nalgunhas delas, por certo, a Risco. Nunha misiva fondamente emotiva do 1 de marzo de 1940, remitida desde Trasalba, o autor de Arredor de si escribía: "¿Quer saber da miña vida? Tranquía, sosegada, afundida no maino devalar dos agros. Teño libros gregos e latinos, teño libros portugueses, papel e tinta, moito vagar e sobre todo saúde e confianza en Deus. Mañán cumprirei os 52 anos. O corpo aínda 
Habería que apuntar algo semellante sobre a perspectiva desenfocada do censor con relación aos demais títulos d'O porco de pé e outras narracións. Importa sinalar, emporiso, que no libro non se reflectía ningunha información referente á súa índole de recompilación nin tampouco á cronoloxía das obras. Isto debeu de conducir a equívoco a quen o inspeccionaba, quen interpretou quizais que eran recentes. É imprescindible non esquecer, por outro lado, o arranque potencialmente confuso, desde o punto de vista do tempo histórico, d'O porco de pé, pois dispuña de entidade suficiente para pór en garda o encargado de avaliar a edición: "Na post-guerra, D. Celidonio ascendéu de porco a marrán e chegóu a Alcalde. A parenta inflóu como o fol da gaita" (Risco, 1972, p. 9).

Como queira que o informe transcrito era parcialmente desfavorable, decidiuse o 1 de decembro que $O$ porco de pé e outras narracións se sometese a unha segunda fiscalización. Efectivamente, o lector $n^{\circ} 8$, que si demostraba non ignorar a transcendencia de Risco como figura intelectual - trátao, por exemplo, máis dunha vez como "profesor"-, rubricaba un xuízo positivo tres días máis tarde:

O porco de pé constituye la pequeña historia de Celedonio Latas Tinajero, un vulgar dependiente de ultramarinos, casado con la hija del dueño del comercio, que llega a ser alcalde de la ciudad y personaje renombrado, enaltecido y homenajeado por una sociedad cambiante y en la que el dinero ocupa el lugar que antaño ocupaba la hidalguía de nacimiento. Se trata, en rigor, de una sátira inmisericorde contra ciertas costumbres caciquiles con carta de naturaleza en

rexo, o esprito mozo. Ningunha ambizón. Pouco baixo ás cidades. Somentes algunha xeira pol'as lembradoiras rúas de Compostela ou pol'as mariñas cruñesas. Algunhas novelas feitas e moitos proieitos vagos. Moitos pesares por amigos mortos. Todos eles máis viventes cada día no recordo. Algún traballo (con pseudónimo) en revistas. Pronto lle mandarei unha: Misión. E abonda de min. (...) O Risco, calado, misterioso, enigmático. Non lle eistrane o seu silenzo. ¡Pasan os homes por raros avatares!". Noutra carta, do 23 de xullo de 1940, Otero Pedrayo trasladáballe a Carlos de Passos, a propósito da actitude de Risco logo do estalido da Guerra Civil: "Está moi ben o de penedo, apricado ao noso enigmático amigo Risco. Fai tempo non o vexo. Xa lle teño recordado a Vde. Sempre cala e sospira". Nunha comunicación máis do 15 de novembro de 1951, Otero Pedrayo aínda escusaba a Risco: "O Risco é moi bó. Está canso, sáenlle as cousas mal. Ten máis anos que eu, traballa rudamente todos os días. A min tampouco me escrebe e a outros amigos. Despois dóese moito". O mesmo volvía facer o 31 de xullo de 1957, agora en castelán: "Disculpe a Risco su silencio. Pasa una vejez dolorosa y agitada por mil pequeñas y diarias preocupaciones". No concernente á pegada de Joyce en $O$ porco de pé revelada explicitamente por Risco, é indispensable observar que Carballo Calero (1975, p. 641) a daba por probable, mais non por indiscutible: "Aínda que resulta moi orixinal, a novela fainos lembrar a Rabelais, Swift, Joyce... Poida que algún destes mestres teña inspirado o recurso estilístico das longas enumeracións humorísticas, moi abondantes en $O$ porco de pé". 
algunas comarcas galaicas, de una parodia de la sociedad política del primer cuarto del siglo XX, de una satírica pintura de usos y costumbres provincianas que tuvieron efectividad y que el profesor Risco personifica en personajes perfectamente reconocibles, como el conde da la narración -el gran amigo de D. Celedonio- y todo su equipo de electoreros y muñidores de elecciones.

Las otras narraciones que el libro recoge -con $O$ porco de pé a la cabeza- ponen de manifiesto el amplio mundo cultural del profesor Risco y el hondo y vivencial conocimiento de la región gallega, cuyo pálpito vital aprisiona y configura en todas y cada una de sus páginas. En sus fantasías y leyendas, en los cuentos que integran el volumen, no deja de percibirse la mutación histórica que se está operando y que Risco capta a través de la erudición de que a veces hace gala; no deja de hacer acto de presencia o de insinuarse cuando menos la llamada modernidad del pensamiento europeo pugnando con el pensamiento castizo y tradicional. Y dicho esto, he de añadir que no encuentro nada que objetar. Pues algunas frases que pudieran ser objetables por sí mismas y aisladamente, en el contexto no significan nada objetable, ya que no pasan de ser como instrumentos obligados de la parodia crítica que el autor elabora, una parodia y una crítica siempre referida a tiempos anteriores al año 1936. Puede autorizarse.

Como doadamente se verifica, o segundo censor era consciente da altura temporal dos textos, que retrotraía sen vacilacións a unha etapa previa á Guerra Civil. Non obstante, o informe do primeiro censor acabaría prevalecendo. Ao cabo duns poucos días, o 6 de decembro con exactitude, trasladábase esta resolución a Galaxia: "Se aconseja la supresión de los pasajes señalados en las páginas 8, 33, 66, 76, 93, 94, 195, 198 y 206”. Ou sexa, todos os elementos riscados por Ángel Aparicio, agás o correspondente á páxina 48.

Faise interesante identificar os ingredientes reprobados d'O porco de pé $e$ outras narracións. Debido ao seu "procomunismo", os anacos que se podaban d'O porco de pé, en particular, eran os seguintes:

E ademáis é unha cousa boa, como vostede pode ver no parágrafo 18 do capíduo II do resume de Bujarín, porque somentes meiante a concentración do capital se pode chegar a unha socialización centralizada da produción, e somentes estando a produción centralizada pódese chegar á orgaización comunista. (Risco, 1972, p. 10)

Los burgueses traidores que nos atropellan / bajo el yugo de la explotación / serán barridos mal y de mala manera / y perseguidos sin compasión! (Risco, 1972, p. 35)

[...] cantando abrazados a Internacional. (Risco, 1972, p. 78) 
[...] pois il era comunista e partidario da independencia de Galicia e da ditadura do proletariado (...). (Risco, 1972, p. 96)

En Os europeos en Abrantes, á súa vez, considerábase "procomunista" a seguinte frase: "[...] vivirían nun culto e tolerable comunismo" (Risco, 1972, p. 208). Por outra parte, como produto do "repugnante espectáculo del aquelarre y sacrílego de la magia negrafilomasonería", determinábanse rexeitables estes dous fragmentos d'O porco de pé:

[...] e o cú recachado beixado das bruxas, que lle deixan nil todolos días, e especialmente o de San Silvestre, o cuspe e as babas dos bicos sin dentes, cansos de rezaren polo día nas eirexas, e sedentos da sede do seu xubileu que somentes se acalma cos beixos que xa só o cú do demo recibe con pacencia, ao tempo que lles dá alento e vida. (Risco, 1972, p. 68)

[...] o das Misas Negras onde se escuartiza un neno non bautizado sobre o corpo encoiro dunha muller, e cómenselle os fígados aínda quentes e ademais chanfaina [...]. (Risco, 1972, p. 68)

Tamén en $O$ porco de pé, en razón da súa "tendencia separatista”, desbotábase este treito:

O noso fin remoto é a emancipación dos labregos de Galicia pra que cheguen a pesar como deben na política da nosa Terra. O noso fin ultimo é que a clás labrega chegue a ser a que goberne a Galicia autónoma, ceibe e redimida. (Risco, 1972, p. 95)

E polo seu "anticlericalismo", extirpábase a aseveración d'Os europeos en Abrantes que segue: "[...] concluíndo dunha vez pra sempre coa tiranía ominosa do Sacerdote...” (Risco, 1972, p. 197). Finalmente, por mor de que destilaba presuntamente un "juicio despectivo de la península ibérica como parte de Europa", refugábase esta reflexión d'O porco de pé: "O apéndice chamado Penínsua Ibérica, arredado de Europa por cinco séculos de cultura, pertence espritualmente ao Sahara" (Risco, 1972, p. 200).

Á vista da notificación oficial, Fernández del Riego entraba en contacto axiña con Piñeiro o 27 de decembro, co obxecto de que se involucrase logo do veredicto adverso do Ministerio de Información y Turismo: "Ahí che van probas das páxinas da narrativa do Risco nas que hai chataduras. Mira o que se pode facer [...]". Con celeridade, Piñeiro respondía xusto un día despois, non disimulando ao comezo o seu abraio polo fallo das autoridades. Así a 
todo, ofrecíase decontado a tentar diminuír o impacto das mutilacións demandadas:

Acabo de recibir as probas do Risco coas chataduras da censura. Supoño que son irremediables, así que non temos máis solución que procurar sentido despóis de suprimir as frases censuradas. En realidade trátase de verdadeiras migalladas que non se comprende ben o motivo que movéu ao censor. Carecen de valor esencial, así que a supresión é puramente caprichosa.

Consecuentemente, Piñeiro pasaba a artellar un comentario meticuloso, con suxestións individuais, para os cortes esixidos de modo imperativo:

Na pax. 10 coido que non se interrumpe o sentido coa supresión do párrafo, que insiste espricativamente na mesma idea xa expresada.

Na pax. 35, a supresión da copla tampouco destrúe o sentido do que sigue, porque a copla é como unha "ilustración".

Na pax. 68, o final do primeiro párrafo non prantexa problemas de sentido. As duas liñas chatadas no segundo párrafo sí que interrumpen a continuidade de sentido, a menos que suprimamos a palabra "chanfaina" para que se restableza continuidade descriptiva.

Na pax. 78 non podemos facer nada máis que prescindir da Internacional.

Na pax. 95, coido que non ten moi bon arranxo. Todo queda reducido á expricación de en que consiste o fin prósimo. Coido que é mellor que diga "Si estades conformes" en lugar de decir "Si estades conformes con estes tres fins", porque só expricóu un deles. Haberá, pois, que deixar a frase reducida a "Si estades conformes".

Na pax. 96 pode facer sentido dificilmente unha vez eliminada a frase chatada. Faríao si a poideramos sustituir por outra equivalente, inda que mais técnica, como por exemplo "..., pois il era partidario do cambio total das estruturas". Non sei si se poden facer estas sustitucións ou non.

Na pax. 197 non podemos aventurar ningunha modificación do suprimido. Hai que se resignar.

Na pax. 200 tampouco podemos facer nada, coido.

Na pax. 208 non vexo máis camiño que aceptar a supresión

Piñeiro exteriorizaba unha derradeira impresión fronte ás pexas, sen esconder novamente a súa perplexidade: "En conxunto, as supresións son máis ben parvadas do censor. Non se ve ningunha verdadeiramente xustificable". Talvez esta observación, polo clarividente diagnóstico que avanzaba, foi o que levou a que Galaxia optase por non se conformar. Tamén debeu de influír en medida importante o feito de que no volume se acreditase como data de saída do prelo o 26 de decembro de 1972. Sen dúbida, a editorial non imaxinara 
que $O$ porco de pé e outras narracións ía tropezar con trabas burocráticas, de maneira que seguramente procedeu con certa confianza.

Desde Galaxia tramitábase, sen dilacións, este persuasivo recurso o 2 de xaneiro de 1973:

Al Ilmo. Sr. Director General de Cultura Popular y Espectáculos.

Editorial Galaxia, S. A., con domicilio en Vigo, calle Reconquista n ${ }^{\circ} 1$, ante V. I. comparece y con el debido respeto expone:

Que en cumplimiento de lo establecido al efecto, ha presentado a consulta previa una breve serie de relatos de Vicente Martínez Risco con el título de $O$ porco de pé e outras narracións, para su ulterior edición en un tomo. La consulta ha sido evacuada, aconsejando la supresión de varios pasajes, señalados en las páginas 8 , 33, 66, 76, 93, 94, 195, 198 y 206.

Sobre el particular debemos manifestar a V. I. que las narraciones de referencia fueron publicadas unas en los años 20, y otras con anterioridad. Se trata, pues, de textos literarios encuadrados en el clima de aquellos tiempos, y que ahora se pretende reeditar. Pero al prescindir de algunos párrafos de los mismos, como se aconseja, surgen problemas que afectan sustancialmente a la continuidad del sentido. Y como, por otra parte, el autor ha fallecido, no existe la posibilidad de realizar correcciones o rectificaciones en los relatos.

Confiamos, pues, en que una nueva lectura objetiva que tenga en cuenta el dato fundamental de la cronología de las narraciones, no hallará motivo para la supresión de los pasajes anteriormente indicados. La razonable tolerancia que permite a conocidos escritores actuales el ejercicio de su capacidad creadora en novelas de gran circulación nacional, no dejará de ser igualmente razonable ante una pequeña serie de relatos publicados en los años veinte, que, además de inspirarse en una época pasada, tendrán una circulación mucho más reducida.

En consecuencia,

Suplica a V. I. que, a la vista de lo alegado, se sirva ordenar una nueva lectura del volumen $O$ porco de pé e outras narracións de Vicente Martínez Risco, autorizando a esta Editora la reedición del mismo en toda su integridad.

Dios guarde a V. I. muchos años.

Como se advirte, as alegacións estaban fundadas con perspicacia, mormente a partir de dous argumentos de refutación complicada. O primeiro residía en remarcar a verdadeira data dos textos agrupados no tomo, todos eles forxados antes da Guerra Civil. A segunda motivación estribaba en facer valer que o autor xa falecera, polo que non se podían materializar as emendas requiridas sen que os textos se visen inevitablemente prexudicados nun estimable grao. 
Por todo o expresado, Galaxia pregaba outra lectura dos orixinais, máis ecuánime, coa esperanza de que non se percibise a necesidade de ningunha supresión. Para reforzar a petición esgrimíase, con habelencia dialéctica, que non poucos escritores autores en español gozaban de superior indulxencia para exhibiren o seu xenio creador. Dábase a entender que suporía un agravio comparativo que, en troques, se obrase con tanto celo cuns relatos de cinco décadas atrás, por riba difundidos nunha lingua minoritaria.

A instancia elevada por Galaxia prosperou, se cadra porque os seus fundamentos estaban perfilados con intelixencia á marxe de semellar obxectivos. En todo caso, non tiña garantido de partida o éxito, porque a localización cronolóxica das obras con anterioridade a 1936 non constituía un factor eximente de seu. É pertinente traer a colación que as obras completas de Ramón Cabanillas, a finais dos anos 50, tiveran que se publicar na Arxentina, logo de recibiren a prohibición da censura, malia que a meirande parte das contribucións que conformaban o repertorio se encadraba nun estadio bastante precedente (Dasilva, 2009a).

No expediente administrativo d'O porco de pé e outras narracións contense que Ángel Aparicio, o primeiro censor, variaba a súa postura o 9 de xaneiro de 1973:

Leídos los pasajes que en un principio consideré rechazables, admito el alegato razonado de la editorial en orden a su desfase en el tiempo y rectifico mi primer informe, pudiendo publicarse íntegramente.

Por conseguinte, o Ministerio de Información y Turismo enviaba esta nova notificación a Galaxia o 11 de xaneiro:

En contestación a su consulta de fecha 5-1-73 acerca de la obra $O$ porco de pé e outras narracións, Vicente Martínez Risco, se le comunica que no se encuentra inconveniente para su edición, de la que deberá, en su día, constituir el depósito previo exigido por la vigente Ley de Prensa e Imprenta.

De conformidade co estipulado no artigo 12 da citada lei, que daquela rexía o funcionamento da censura, o 28 de febreiro de 1973 cumpríase a prescrición do depósito oficial de seis exemplares d'O porco de pé e outras narracións. Na nota de presentación recollida na solapa do volume facíase fincapé, poida que por cautela, en que $O$ porco de pé se insería nun marco pretérito, aínda que 
dalgunha forma non caducado, destacando asemade a dimensión paródica despregada por Risco:

Na súa pluma brilla sempre unha puntiña de ironía que é como un centileo da intelixencia frente ás contradicións e as limitacións da vida ao bater coa realidade. Trátase dun humor acentuadamente irónico, doado, si tal quixer, para o cultivo da sátira. E un bo exemplo desta actitude satírica témolo xustamente en $O$ porco de pé, que aínda hoxe, desaparecida a realidade inmediata que inspirara ao Risco cando o escribiu vai para medio século, conserva viva e vixente toda a gracia intelectual dunha visión satírica de boa lei. (Risco, 1972)

\section{O expediente de censura de La puerta de paja}

No eido da expresión en español, Risco achou impedimentos para estampar La puerta de paja (Risco, 1953), presentada ao Premio Nadal en 1952 e ao Premio Ciudad de Barcelona o ano seguinte. Ao primeiro dos certames concorrera, por outra banda, Los que se fueron, da autora tamén galega Concha Castroviejo (Varela Jácome, 1963). Carlos Casares fíxose eco da prometedora traxectoria de La puerta de paja no prestixioso concurso, onde permaneceu en cabeza nas votacións ata quedar relegada no último momento "ao terceiro lugar, detrás de Nosotros, los Rivero de Dolores Medio e de La ciudad sin horizontes de Severiano Fernández Nicolás" (Casares, 1981, pp. 183-184).

A editorial Planeta daría á imprenta La puerte de paja envolta, pola súa estraña derrota, nunha especie de polémica que xerou notorias expectativas, segundo Manuel Casado Nieto referiu:

Engadirei somentes que cando a novela, após de ir en cabeza en sucesivas votacións, apareceu de sócato eliminada dun xeito insólito e dificilmente explicable. La Puerta de Paja non gañou o premio, pero tivo resonancias previas e subseguintes á súa publicación, raramente ou nunca vistas naqueles anos. Pediuma Lara, dono da Editorial Planeta, cunha oferta tentadora, e eu concertei con el a publicación, previo permiso do autor, naturalmente. (Casado Nieto, 1984, p. 490)

Naquela carta de Piñeiro a Losada do 14 de maio de 1963, arriba evocada, asegurábase precisamente a implicación activa nos primeiros pasos de $\mathrm{La}$ puerta de paja de Casado Nieto, quen desenvolvía en Barcelona o seu labor profesional como fiscal, unido a Risco por estreitos lazos de amizade: 
Eran máis ou menos veciños, pois os Risco proceden do Castro Caldelas, onde o D. Vicente tiña algunha leira. Eran vellos amigos. O Casado volcou toda a súa influencia persoal e política para lle conquerir algún premio barcelonés a $L a$ puerta de paja, e levou a Risco ahí. (Piñeiro e Losada, 2009, p. 232)

No que fai á recepción satisfactoria da obra, que merecería futuras edicións tanto en México (Risco, 1955) como en territorio español (Risco, 1960), paga a pena traer á memoria a caracterización encomiástica, nunha recensión coetánea, de Manuel G. Cerezales (1953), quen puña o acento na súa acusada peculiaridade:

Vicente Risco ha escrito con La puerta de paja una novela desconcertante, emancipada de los cánones que prescriben la literatura narrativa moderna española, absolutamente independiente de las corrientes estéticas que arrastran a nuestros novelistas jóvenes, a los buenos y a los malos.

Nunha dirección análoga, José Trapero Pardo (1953) apuntaba que Risco acadara o "triunfo -sin la peneira algo descalibrada del Nadal-por sus méritos propios y por sus pasos contados, pero contados por horas de estudio y de trabajo". Para José Ángel Valente (1953), La puerta de paja resultaba, sinxelamente, "fuera de serie y señera”. Polo seu lado, Antonio Vilanova (1954) catalogaba a aposta de Risco de "magnífica novela", onde os seus "relevantes méritos" coadxuvaban a "contrarrestar sobradamente los evidentes fallos de su estructura y concepción novelesca".

Na monografía Novelistas españoles de los siglos XIX y XX, Domingo Pérez Minik (1957, p. 322) eloxiaba que La puerta de paja se erixía no "mirlo blanco de extraño vuelo" da actual literatura española. E na excelente La novela española contemporánea (1927-1960), Eugenio de Nora (1962, p. 71) insistía en que eran "muchos, en efecto, los motivos para admirar y sorprender al lector de La puerta de paja", aínda que simultaneamente os había "para hacerle sentirse desorientado y perplejo". Como balance, este crítico coidaba que a novela entrañaba, definitivamente, "una invención altamente original y sugestiva, especiada con los dilatados y extraños saberes de su autor" (Nora, 1962, p. 76).

O mesmo José Manuel Lara, fundador de Planeta, pregoaba nunha entrevista, non sen caer en hipérbole, que La puerta de paja simbolizaba a novela "mejor que se ha escrito en España en lo que va de siglo" (Costa Clavell, 
1954). A seguir, confesáballe ao xornalista o seu desconcerto porque non se impuxese en ningunha das competicións literarias en que participara:

Indiscutiblemente, la novela de su ilustre paisano debió haber ganado ambos premios. Hasta cierto punto me explico que no haya ganado el Nadal, teniendo en cuenta que se trataba de un premio concedido por una editorial, en cuya concesión pudo haber influido el que la novela fuese más o menos comercial; pero lo que no me explico, ni me explicaré nunca, es que no haya ganado el Ciudad de Barcelona, que debe ser concedido a una novela única y exclusivamente por su valor literario. $\mathrm{Y}$ en esto estaba muy por encima de todas las presentadas la de Risco. Sin embargo, quedó en segundo lugar...

Foi Casado Nieto (1984, p. 490), espectador próximo das vicisitudes de $\mathrm{La}$ puerta de paja, o que destapou por primeira vez os obstáculos que sufriu cando a censura a escrutou:

Direi para coñecemento de todos e agalio de moitos que custou traballo atinxir a autorización da censura, e que, se afinal se conseguíu, debeuse ás xestións dun home intelixente, o Dr. Iglesias, profesor numerario da Universidade de Barcelona, que era ademáis Delegado de Información e non sin loita arrincou o libro das poutas do lápiz roxo...

A principios dos anos 80, o xornalista Fernando Salgado esforzaríase en recuperar o texto deturpado de novela (Risco, 1981), adoptando como base illada para ese fin un mecanoscrito ao que accedera:

En la copia mecanografiada que obra en mi poder, encuadernada por Gráficas Tanco (Orense, 1952), además del título, figura un subtítulo: Crónica del obispo Baldonio. En la cubierta lleva un dibujo a plumilla, original de Vicente Risco. (Salgado, 1981, p. 4)

Nesta edición, como reclamo publicitario, anunciábase na cuberta posterior:

Dos de las tres novelas que integran este volumen -Gamalandalfa y La verídica bistoria del niño de dos cabezas de Promonta- conocen la luz por primera vez. La tercera -La puerta de paja-, finalista del Premio Nadal en 1952, aunque ya conoció dos ediciones nunca había llegado íntegra al lector, víctima de los tijeretazos y mojigaterías de la censura franquista. (Risco, 1981)

No limiar, Salgado falaba da acción das tesoiras no tránsito de La puerta de paja polo Ministerio de Información y Turismo, que ilustraba con dous exemplos unicamente. $\mathrm{O}$ primeiro era o seguinte: 
Los cuernos le habían sido presentados después por un familiar, en una bandeja repujada. Baldonio dirigió una sibilina pregunta a su bufón. (Risco, 1953, p. 9)

Los cuernos le habían sido presentados después por un familiar, en una bandeja repujada. Baldonio se los probó apoyándolos en las sienes por la raíz, pensando en su barragana favorita, y preguntó al bufón cómo le sentaban; el bufón le respondió que se conocía muy bien que Rosinda los había hecho expresamente para él, pero se había excedido un tanto o más en la medida. (Risco, 1981, p. 13)

\section{O segundo situábase aquí:}

No era posible que un ángel tuviera aquellos descomunales cuernos de ciervo... Se los había regalado Rosinda, en una bandeja repujada. (Risco, 1953, p. 42)

No era posible que un ángel tuviera aquellos descomunales cuernos de ciervo... Pero estos cuernos de ciervo los había arrancado Finamor de las sienes del obispo, Baldonio los tuvo puestos alguna vez, acaso otras veces, acaso siempre. Se los había regalado Rosinda, en una bandeja repujada. (Risco, 1981, p. 33)

Alén diso, nesta versión supostamente auténtica de La puerta de paja aludíase a transformacións de orde lingüística, executadas polas propias editoriais, as cales non se acataban por se conceptuaren de envergadura escasa:

Aparte de otras modificaciones sin importancia, tanto Planeta como Libros Plaza corrigen algunos galleguismos del autor (cardenales en vez de mazaduras, a rastras por arrastro, etc.), que nosotros preferimos dar en su redacción original. Se trata, no obstante, de cambios poco significativos, ya que los galleguismos no pasan de ser "despistes" de Vicente Risco, a diferencia de lo que ocurre en Gamalandalfa, donde se utilizan con abundancia y ayudan a crear el "clima gallego" de esta obra. (Salgado, 1981, p. 7)

Olivia Rodríguez González, en estudos ulteriores (1998-1999, 2001), deslindaría outras alteracións en La puerta de paja provocadas polo papel da censura, que clasificaba como morais e relixiosas. En canto ás primeiras, reiteraba as dúas evidencias descritas por Salgado. En calidade de omisións da segunda clase, subministraba estas (Rodríguez González, 1998-1999, p. 245; 2001, p. 262):

"Ahora, él me lleva a Roma.... ¿Es realmente Finamor, o es Satanás, mi pequeño Satanás, o quizás Ascanio, el que tienen por santo? (Risco, 1953, p. 20)

"Ahora, él me lleva a Roma.... ¿Es realmente Finamor, o es Satanás, mi pequeño Satanás, o quizás Ascanio, el que tienen por santo? No hay santos, nunca los hubo... Son cosas de las viejas, de las monjas... (Risco, 1981, p. 20) 
Si yo pudiese llegar a cardenal, quizá alcanzara también a conseguir... ¡Oh!... (Risco, 1953, p. 21)

Si yo pudiera llegar a cardenal, quizá pudiera llegar a conseguir que Rosinda fuera Papisa... ¿Por qué no ha de haber una Papisa? Con Rosinda, Venus, la diosa del amor humano, se sentaría en la silla de San Pedro; al principio no lo sabría nadie: Rosinda no sería Papisa, Rosinda sería Papa. Siendo Papa Rosinda me coronaria Emperador. (Risco, 1981, p. 21)

Pola nosa parte, postulamos noutro lugar que hai que discernir obrigatoriamente dous períodos na investigación da influencia exercida pola censura franquista nas letras galegas (Dasilva, 2020a), os cales teñen especial incidencia no referente a Risco: $1^{\circ}$ ) período predocumentado; e $2^{\circ}$ ) período documentado. O primeiro definiríase pola non utilización das fontes documentais primarias, isto é, os expedientes de censura procedentes do Ministerio de Información y Turismo, gardados no Archivo General de la Administración. O segundo período singularízase xa polo uso de tales fontes documentais primarias.

En realidade, o expediente de censura de La puerta de paja depara informacións preciosas que axudan a reconstruír a súa supervisión polos xerarcas da 20 ditadura, desmentindo nun nivel substancial, como se comprobará deseguida, o que se tiña afirmado ata arestora. Así, subscrita a solicitude de autorización o 3 de febreiro de 1953 pola editorial, sábese que Florentino Pérez Embid, Director General de Información, facía chegar a Joaquín Ubeda, Jefe de la Sección de Inspección de Libros, un aviso discrecional o 17 de febreiro:

Habrá llegado, hace unos días o estará a punto de recibirse en esa Sección, un original de la obra de D. Vicente M.-Risco Agüero, titulada La puerta de paja. Cuida de que dicho original sea entregado a lector de reconocido buen criterio.

Esta recomendación obtiña resposta aos dous días:

Contestando a la Nota que antecede, cumple manifestar a V. I. que la obra de D. Vicente M.-Risco Agüero, titulada La puerta de paja, Exp. 830-53, ha sido entregada, según sus indicaciones, a la lectura del Lector $n^{\circ} 1$, Dr. Enrique Conde Gargollo.

Con suma dilixencia, o censor nomeado aos efectos puña a sinatura ao pé do seu informe o 20 de febreiro: 
Es una farsa novelesca en un ambiente medieval, escrita en tono irónico y humorístico - caricatura de aquel Renacimiento que sitúa en Nerbia, ciudad de un país imaginario- y con un buen estilo literario.

El Obispo Baldonio -figura central- es un tipo hipomaniaco, con personalidad paranoide -excomulgado por el Papa-, es un Señor de sus tierras y vasallos, mujeriego, epicúreo, increyente, rebelde y escandaloso... pero al fin le llega su temor y humillado y penitente llega a Roma para solicitar la Gracia.

Allí está la Puerta de Paja -simbolismo soñado- que es alimento de bestias y obstruye la Razón humana, su fe recobrada supera la Paja materialista. Limpio de sus pecados regresa a Nerbia, y el pueblo injusto con el Obispo Baldonio arrepentido, le mata.

Puede autorizarse con tachaduras.

As partes que "atacaban a la Iglesia o a sus ministros", consonte se invocaba no informe do censor, ascendían a cinco. Amais das catro anotadas por Salgado e Rodríguez González, estaba esta:

Baldomiro pensó: "Es mi Ángel de la Guarda, me lleva a Roma, me lleva a pedir perdón al Papa, quiere que pida perdón al Papa... No es el Ángel de mi guarda, es Finamor, mi sobrino, que quiere a Rosinda para sí... (Risco, 1953, p. 21)

Baldomiro pensó: "Es mi Ángel de la Guarda, me lleva a Roma, me lleva a pedir perdón al Papa, quiere que pida perdón al Papa para que abandone a Rosinda, para que me separe de Rosinda y se la deje para él. Quiere que se la deje para él... No es el Ángel de mi guarda, es Finamor, mi sobrino, que quiere a Rosinda para sí... (Risco, 1981, p. 21)

Á luz do expediente de censura de La puerta de paja, non cabería xulgar atinada a proposta restauradora acometida por Salgado, a cal se asumiu fielmente máis adiante nas Obras completas de Risco editadas por Galaxia (Risco, 1992). En efecto, está incorporado no mesmo un mecanoscrito coincidente presumiblemente con aquel do que se valeu este editor. Ora ben, existen no expediente tamén unhas galeradas consecutivas, con correccións derivadas da presenza de galeguismos, desleixos estilísticos e erros tipográficos, que están detrás da versión proporcionada orixinariamente ao público. Tales descoidos explicaríanse pola velocidade coa que Risco fabricou La puerta de paja, a teor do que Casado Nieto atestou con todo vagar, no "Prólogo" que a encabezaba, sobre o seu apurado parto:

Iba a concluir por aquella vez -1952 - mi divagante coloquio de dos meses con Vicente Risco, año tras año reiterado en la estival holganza, fecundo siempre en sabias enseñanzas de aquel gran maestro del que tantos jóvenes hemos apren- 
dido - tan aprendidas, que se nos incrustaron en el alma- las cuatro o seis nociones esenciales de todo bien compuesto andamiaje mental. Iba a terminarse aquel delicioso dialogar, anualmente renovado sobre un picacho de las montañas de Orense, a caballo de manadas de castaños, frente a dilatados horizontes de vides, centenos y praderío, pródigo en oscuros bueyes que discurren lentos, sin contar jamás, ni ellos ni nosotros, las horas que anuncia para nadie una campana empinada en la más vieja torre de una fortaleza.

Y he aquí que él, Vicente Risco, interrumpe de pronto aquella semisomnolencia avanzando por la sala con unos pliegos en la mano, de apretada caligrafía, semejante a patas de moscas:

- Mira esto. Es una cosa un poco rara que se me ha ocurrido escribir esta tarde. Se trata de un obispo de otra edad, excomulgado. Pudiera ser el primer capítulo de una novela... Lee, y dime qué te parece. [...]

Han transcurrido solo tres semanas. El lector, cuya cabeza apenas emerge de los rimeros de legajos acumulados en su mesa, tiene ahora ante sí una carta manuscrita, como garrapateada por patas de mosca, y en los ojos un brillo de sorpresa y de gozo: la misiva anuncia que aquellos extraños renglones en que se comenzaba a narrar peripecias de la vida de un prelado legendario, habíanse convertido en una novela de título desconcertante, La Puerta de Paja [...]. (Casado Nieto, 1953 , pp. 5-6) ${ }^{3}$

Nunha nota de benvida á obra, na revista Ateneo, o xornalista e escritor Juan Fernández Figueroa (1953, p. 23) daba noticia dunha carta persoal de Risco onde este facilitaba unha aclaración similar con non menos detalle:

Fue escrita en unos veinte días, sin plan, sin asunto, sin saber lo que iba a hacer, sin meditar, poniéndome a escribir a lo que saliese, casi escritura automática, sin parar, sin saber cómo desenlazar los líos que se iban armando, rompiendo por donde pude, y sin embargo, poco a poco, fue tomando coherencia, ella sola, hasta acabar de un modo que ya me parece no solo demasiado racional, sino demasiado real. Caí en los lazos de la razón, de los que había pretendido huir. ¿Qué le parece?

3 Con algunhas variantes, Casado Nieto volvería relatar, pasados trinta anos, a xénese de La puerta de paja: "Verbo desto lémbrome concretamente do seu inacabado libro El Caos y el Orden, publicado incompleto póstumamente co título de Orden y Caos, e doutro titulado Los Arquetipos, moi interesante por certo, do que non volvín saber máis, quizais traspapelado ou perdido por algún editor. Tamén da novela La Puerta de Paja. Unha tarde frieira do mes de setembro quentábase diante dunha cheminea da miña casa, calado, coma ensumido en cavilacións. Respetámoslle o silencio. Ao día seguinte chegounos cun monllo de folios nos que encetaba unha novela: "Sentado a la lumbre, el Obispo Baldonio, excomulgado por tres Papas seguidos, etc., etc.". Resultou que o víspora, naqueles intres de silencio concentrado, sentado ao lume, coma o bispo feudal, concebira a idea novelística, e ao chegar á súa casa puxérase de contado a trasladar ao papel o comenzo da orixinalísima historia, que logo seguiu narrando a velocidade vertixinosa, deica rematala nunhas dúas semás, sin deixar de nos ler o que escribía a cotío" (Casado Nieto, 1984, p. 490). 
Y no solo tomó coherencia, sino sentido. Lo que acaso no iba a significar nada, resulta que ahora, después de hecha, tiene un significado o más. Esto prueba que para que salgan las cosas, no hay como abandonarse al azar. Jamás me hubiese salido una cosa así -vamos a suponer que, en efecto, es buena, como dicen...-, jamás me hubiera salido si la hubiera meditado.

En boa lóxica, hai que pensar que tales mudanzas no texto editado de $L a$ puerta de paja, provenientes das galeradas, gozarían do visto e prace do autor. Unha proba ostensible é que non só se plasmaron na primeira edición, senón que se perpetuaron nas edicións de 1955 e 1960, con Risco aínda vivo. Por todo iso, calquera tentativa de restitución de La puerta de paja debe repoñer, claro está, aquilo que a censura estragou, pero non máis. Por establecermos un paralelismo esclarecedor, a rehabilitación do texto xenuíno d'A esmorga e Xente ao lonxe, de Eduardo Blanco Amor, concentrouse nos recortes decretados polo Ministerio de Información y Turismo (Dasilva, 2009b, 2013, 2020b). Outro tanto debería acontecer con Aquella gente..., autotradución de Xente ao lonxe. Neste caso, as persoas encomendadas pola editorial Seix Barral para repasar o manuscrito expurgaron os galeguismos da versión, mais sen que Blanco Amor consentise esa inxerencia, pois eran intencionados (Dasilva, 2021).

Contrariamente a esta conduta, Risco aceptou a revisión practicada nas galeradas de La puerta de paja, onde se constata que o texto primixenio do mecanoscrito, máis alá de que se limparon erratas, se depurou idiomática e estilisticamente. Véxase como a edición de Salgado resucita o galeguismo "y si cuadra", substituído na primeira edición, e non respecta algunhas intervencións ortográficas:

Creemos que vamos a salvar la vida y la salud de una persona que tanto preciamos, $y$ si cuadra, lo que hacemos es destruirla. ¿No véis que para cada uno hay un día en que nada valen la naturaleza ni la facultad? (Risco, 1981, p. 30)

Creemos que vamos a salvar la vida y la salud de una persona que tanto preciamos, $y$ si acaso, lo que hacemos es destruirla. ¿No veis que para cada uno hay un día en que nada valen la Naturaleza ni la Facultad? (Risco, 1953, p. 36)

Entre outras cousas, incorre nun lapsus xa solucionado:

Si fuese verdad todo lo contrario de lo que para él había sido el mundo, todavía él desearía negarlo y rechazarlo... Pero tenía que confesar, allá tan adentro que casi no podía negarse, que así era, había perdido enteramente toda su vida... (Risco, 1981, p. 131) 
Si fuese verdad todo lo contrario de lo que para él había sido el mundo, todavía él desearía negarlo y rechazarlo... Pero tenía que confesar, allá tan adentro que casi no podía llegarse, que así era, había perdido enteramente toda su vida... (Risco, 1953, p. 211)

$\mathrm{Na}$ edición de Salgado mesmo se prescinde de compoñentes da primeira edición, coma este:

Falconete no supo qué contestar.

De allí a poco, el obispo pidió algún alimento y le trajeron leche con miel.

Después de tomarlo, dijo:

-Trae mi manto de piel. (Risco, 1981, p. 48)

Falconete no supo qué contestar.

De allí a poco, el obispo pidió algún alimento y le trajeron leche con miel. - ¿Ves, Falconete? Buena señal. La Tierra de promisión manaba leche y miel.

Después de tomarlo, dijo:

-Trae mi manto de piel. (Risco, 1953, p. 66)

En síntese, a restauración de La puerta de paja, que representa unha tarefa aínda pendente na actualidade, deberá basearse inescusablemente no rescate 24 das porcións retiradas por presión da censura, por unha parte, e na fidelidade aos axustes verbais intercalados nas galeradas da primeira edición, por outra.

\section{Cabo}

A conclusión primordial que se tira é que Risco, a pesar da súa afervoada adhesión ao franquismo, non se salvou da esculca dos censores, se ben con desenlaces dispares. A verdade é que o autor de Teoría do nacionalismo galego xa tivera oportunidade, antes da Guerra Civil, de soportar o peso da censura. El mesmo fixérase eco, a mediados dos anos 20, das restricións que o autoritarismo de Primo de Rivera aplicaba ás principais tribunas do galeguismo. Así, nun artigo daquelas datas na revista arxentina Céltiga, non ocultaba que A Nosa Terra vira reducido o seu quefacer ao plano literario, e que Nós se suspendera á forza durante dous anos (Risco, 1927c).

De xeito paradoxal, Risco matinaría en plena posguerra verbo da censura relixiosa, aquela que se cebaría logo en La puerta de paja, nunha colaboración na revista Misión, tras o pseudónimo Jerónimo de Castro, co significativo 
título "Autores prohibidos". De inicio, admitía que se tornaba "preciso reconocer que es esta una de las cuestiones más espinosas y difíciles" (Castro, 1947). Agregaba, a continuación, cunha prudente equidistancia:

Sin tratar de decidirla, pues alguien con mayor autoridad hay para hacerlo, no estaría mal que quien se sienta con verdadero celo por la verdad y por la unidad de la fe, aportase, a título informativo, sus observaciones.

O máis sorprendente, aínda que só ata certo punto tomando en consideración o seu devir ideolóxico, é que Risco preconizaba unha solución de compromiso que procuraba conciliar en van a coacción e a liberdade:

[...] es justísimo que la autoridad de la Iglesia y la del Estado se opongan a la divulgación de una literatura perjudicial para la fe y para las costumbres de los cristianos, pero, por otra parte, también parece no justo privar a los buenos cristianos del provecho que pudieran sacar de una parte de esa literatura, que contiene ideas acertadas y útiles en el campo de la ciencia, las artes literarias y las artes plásticas.

\section{Referencias bibliográficas}

Arias Chachero, P. (2020). O historiador portugués Carlos de Passos e a súa relación cos intelectuais galegos. O epistolario con Vicente Risco (1934-1954). Grial, 227, 41-53.

Bobillo de la Peña, F.-J. (1980). Nacionalismo e ideología en Vicente Risco. Universidad Complutense de Madrid.

Carballo Calero, R. (1975). Historia da literatura galega contemporánea. Editorial Galaxia. [2 $2^{\mathrm{a}}$ ed.]

Casado Nieto, M. (1953). Prólogo. En V. Risco, La puerta de paja (pp. 5-8). Planeta.

Casado Nieto, M. (1984). Vicente Risco, o home. Grial, 86, 489-504.

Casares, C. (1981). Vicente Risco. Editorial Galaxia.

Castro, J. de (16 de agosto de 1947). "Autores prohibidos". Misión, 409, 5.

Cerezales, M. G. (2 de xullo de 1953). La Puerta de Paja. La Noche.

Costa Clavell, J. (3 de marzo de 1954). El editor Lara afirma que La puerta de paja, de Risco, es la mejor novela publicada en lo que va de siglo. El Progreso. 
Dasilva, X.-M. (2009a). O que a censura cortou da obra de Ramón Cabanillas. Grial, $183,142-147$.

Dasilva, X.-M. (2009b). As vicisitudes editoriais d'A esmorga. Grial, 184, 36-51.

Dasilva, X.-M. (2013). A prol dunha versión non censurada de Xente ao lonxe. Grial, 197, 118-133.

Dasilva, X.-M. (2020a). El estado de la investigación sobre la censura franquista en las letras gallegas. En M $M^{\mathrm{a}}$ J. Olaziregi e L. Otaegi (Eds.), Censura y literatura. Memorias contestadas (pp. 45-61). Peter Lang.

Dasilva, X.-M. (2020b). La restauración de la literatura gallega censurada por el franquismo. Insula, 886, 16-20.

Dasilva, X.-M. (2021). Censura y autocensura en la autotraducción: Xente ao lonxe / Aquella gente..., de Eduardo Blanco Amor. Hermeneus. Revista de Traducción e Interpretación, 23. [No prelo]

Fernández Figueroa, J. (1 de outubro de 1953). La puerta de paja. Ateneo, 43, 23.

Lorenzo Modia, M.-J. (1994). Dédalus en Compostela (Pseudoparáfrasis). Vicente Risco. En A. R. de Toro Santos e F. García Tortosa (Eds.), Foyce en España (pp. 121-132). Universidade da Coruña.

Nora, E. G. de (1962). La novela española contemporánea (1927-1960). Editorial Gredos.

Pérez Minik, D. (1957). Novelistas españoles de los siglos XIX y XX. Guadarrama.

Piñeiro, R. e Losada, B. (2009). Do sentimento á conciencia de Galicia. Correspondencia (1961-1984). Xunta de Galicia-Editorial Galaxia.

Risco, V. (1919). Do caso que ll'aconteceu ô Dr. Alveiros. Tipografía d'El Noroeste.

Risco, V. (1925). O lobo da xente. A trabe de ouro e a trabe de alquitrán. Lar.

Risco, V. (15 de marzo de 1927a). Os europeos en Abrantes. Epopeia en prosa. Nós, 39, 1-7.

Risco, V. (15 de abril de 1927b). Os europeos en Abrantes (Proseguimento). Nós, 40, 5-8.

Risco, V. (25 de xullo de 1927c). Da Renacencia Galega. A revista Nós. Céltiga. Edición extraordinaria. 
Risco, V. (1928). O porco de pé. “Nós” Pubricacións Galegas e Imprenta.

Risco, V. (1953). La puerta de paja. Planeta.

Risco, V. (1955). La puerta de paja. Edición Latino Americana.

Risco, V. (1960). La puerta de paja. Ediciones G. P.

Risco, V. (1961). Leria. Editorial Galaxia.

Risco, V. (1972). O porco de pé e outras narracións. Editorial Galaxia.

Risco, V. (1981). Obra completa 2. La puerta de paja. Gamalandalfa. La verídica historia del niño de dos cabezas de Promonta. Akal Editor.

Risco, V. (1992). Obras completas 2. La puerta de paja. Gamalandalfa. La verídica historia del niño de dos cabezas de Promonta. Doce años después. La tiara de Saithaphernes. Relatos. Poesía. Editorial Galaxia.

Rodríguez González, O. (1998-1999). Vicente Risco e La puerta de paja: Unha valiosa contribución á novela "católica" na posguerra española. Revista de lenguas y literaturas catalana, gallega y vasca, 6, 243-258.

Rodríguez González, O. (2001). La obra narrativa de Vicente Risco. Universidad Complutense de Madrid.

Salgado, F. (1981). Prólogo. En V. Risco, Obra completa 2. La puerta de paja. Gamalandalfa. La verídica bistoria del niño de dos cabezas de Promonta (pp. 3-10). Akal Editor.

Sen sinatura (1954). Denuncia diante a Unesco da perseguizón do idioma galego pol-o Estado Hespañol.

Trapero Pardo, J. (7 de xullo de 1953). Novelistas gallegos. La Puerta de Paja. El Progreso.

Valente, J. A. (1953). La puerta de paja. Índice, 65-66.

Varela Jácome, B. (19 de xaneiro de 1963). Novelistas gallegos en el Premio Nadal. III. La fantasía de La puerta de paja y la realidad de Los que se fueron. La Noche.

Vilanova, A. (6 de febreiro de 1954). La puerta de paja, de Vicente Risco. Destino, 861, 23. 